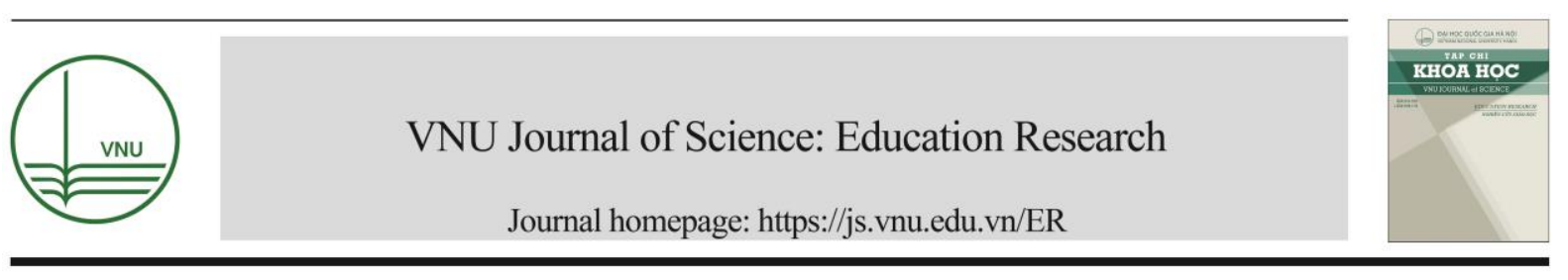

Review Article

\title{
Innovation and Improving Student Training Quality of Philology Education Program to Meet Requirements of the 2018 Philology Curriculum
}

\author{
Pham Thi Thu Hien* \\ VNU University of Education, 144 Xuân Thuy, Cau Giay, Ha Noi, Viet Nam \\ Received 16 September 2019 \\ Revised 20 September 2019; Accepted 23 September 2019
}

\begin{abstract}
The new Philology Curriculum was launched at the end of 2018. This curriculum has many new points, but the most significant is the requirement for teaching informational texts and teaching to develop literacy competency for students. Therefore, it is necessary to renovate and improve the quality of training students in Philology Education Program by updating the content of some current modules, introducing new modules to help students after upon graduation, meet the requirements of the 2018 Philology Curriculum.
\end{abstract}

Keywords: Informational text, literary competency, The Degree of Bachelor in Philology Teacher Education, Philology Curriculum.

\footnotetext{
${ }^{*}$ Corresponding author.

E-mail address: hienpham170980@gmail.com

https://doi.org/10.25073/2588-1159/vnuer.4288
} 


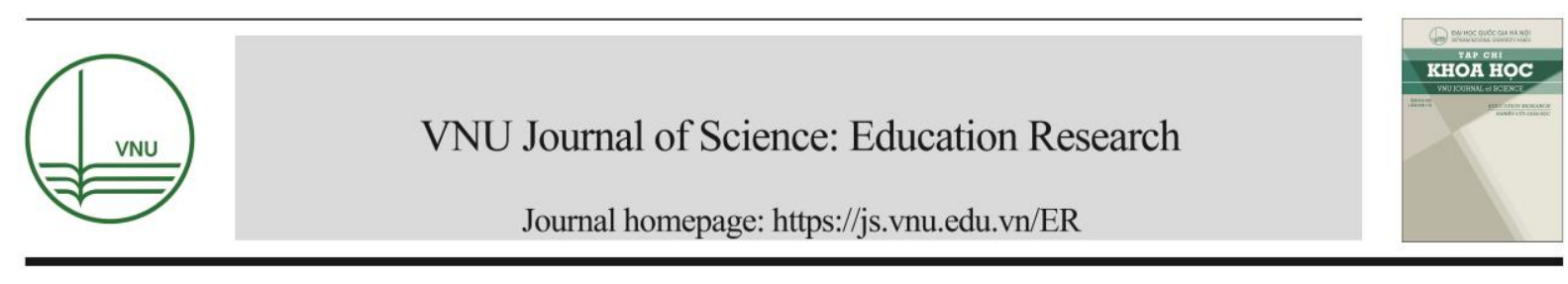

\title{
Đổi mới và nâng cao chất lượng đào tạo ngành Sư phạm Ngữ văn đáp ứng yêu cầu của Chương trình giáo dục phổ thông môn Ngữ văn 2018
}

\author{
Phạm Thị Thu Hiền* \\ Truờng Đại học Giáo dục, Đại học Quốc gia Hà Nội, 144 Xuân Thủy, Cầu Giấy, Hà Nội, Việt Nam \\ Nhận ngày 16 tháng 9 năm 2019 \\ Chỉnh sửa ngày 20 tháng 9 năm 2019; Chấp nhận đăng ngày 23 tháng 9 năm 2019
}

\begin{abstract}
Tóm tắt: Chương trình giáo dục phổ thông môn Ngữ văn mới đã được ban hành cuối năm 2018. Chương trình có nhiều điểm mới, nhưng đáng kể hơn cả là yêu cầu về dạy học văn bản thông tin và dạy và học để phát triển năng lực văn học cho học sinh. Vì vậy, cần phải đổi mới và nâng cao chất lượng đào tạo sinh viên ngành Sư phạm Ngữ văn bằng cách cập nhật nội dung của một số học phần hiện hành, đưa vào chương trình đào tạo các học phần mới để giúp sinh viên sau khi ra trường đáp ứng được yêu cầu của chương trình môn Ngữ văn 2018.
\end{abstract}

Tù khóa: Văn bản thông tin, năng lực văn học, cử nhân Sư phạm Ngữ văn, chương trình giáo dục phổ thông môn Ngữ văn.

\section{1. Đặt vấn đề}

Hiện nay, nước ta có 14 trường đại học tham gia đào tạo cử nhân ngành Sư phạm Ngữ văn. Phần lớn người học sau khi ra trường sẽ tham gia vào việc giảng dạy Ngữ văn ở các trường phổ thông trên cả nước. Để đáp ứng được mục tiêu này, chương trình đào tạo của các trường đại học sư phạm phải luôn cập nhật những yêu cầu của thực tiễn, đồng thời đi trước đón đầu những thay đổi của việc dạy học Ngữ văn ở trường phổ thông trong tương lai.

Tuy nhiên, chương trình đào tạo ngành $\mathrm{Su}$ phạm Ngữ văn của hầu hết các trường đại học ở

\footnotetext{
* Tác giả liên hệ.

Địa chi email: hienpham170980@ gmail.com

https://doi.org/10.25073/2588-1159/vnuer.4288
}

nước ta đã được xây dựng và thực hiện từ lâu, chủ yếu nhằm đào tạo giáo viên đáp ứng yêu cầu của Chương trình giáo dục phổ thông môn Ngữ văn hiện hành đã được ban hành năm 2006 (gọi tắt là Chương trình 2006). Đến thời điểm này, cần có những đổi mới về chương trình đào tạo nhằm nâng cao năng lực của sinh viên ngành Sư phạm Ngữ văn, đáp ứng yêu cầu của Chương trình giáo dục phổ thông môn Ngữ văn mới đã được ban hành cuối năm 2018 (gọi tắt là Chương trình 2018).

2. Mục tiêu và nội dung giáo dục của Chương trình giáo dục phổ thông môn Ngữ văn (2018)

\subsection{Muc tiêu}


Chương trình Ngữ văn 2018 được xây dựng theo định hướng phát triển phẩm chất và năng lực học sinh. Một trong những mục tiêu lớn và quan trọng nhất của chương trình là "giúp học sinh phát triển năng lực ngôn ngữ và năng lực văn học: rèn luyện các kĩ năng đọc, viết, nói và nghe; có hệ thống kiến thức phổ thông nền tảng về tiếng Việt và văn học, phát triển tư duy hình tượng và tư duy logic, góp phần hình thành học vấn căn bản của một người có văn hoá; biết tạo lập các văn bản thông dụng; biết tiếp nhận, đánh giá các văn bản văn học nói riêng, các sản phẩm giao tiếp và các giá trị thẩm mĩ nói chung trong cuộc sống" [1].

Mục tiêu này đáp ứng yêu cầu của thực tiễn và xu thế quốc tế trong dạy học Ngữ văn ở trường phổ thông hiện nay.

\subsection{Nội dung giáo dục}

Nội dung giáo dục - theo Chương trình 2018 - “được xác định dựa trên các yêu cầu cần đạt của mỗi lớp, gồm: hoạt động đọc, viết, nói và nghe; kiến thức (tiếng Việt, văn học); ngữ liệu" [1]. Theo quy định của chương trình, học sinh phải làm việc với các văn bản văn học, văn bản thông tin, văn bản nghị luận để tiếp nhận (đọc và nghe) và tạo lập (viết và nói) các loại văn bản này.

So với Chương trình 2006, Chương trình 2018 có 3 điểm mới, đó là:

(1) Trong số các văn bản mà Chương trình 2018 yêu cầu học sinh tiếp nhận và tạo lập, văn bản thông tin là một loại văn bản mới, chưa xuất hiện ở Chương trình 2006. Theo Chương trình 2018, "văn bản thông tin" là "văn bản chủ yếu dùng để cung cấp thông tin" [1]. Loại văn bản này gồm cả những văn bản được tạo lập theo lối truyền thống và văn bản đa phương thức, trong đó văn bản đa phương thức là những "văn bản có sự phối hợp phương tiện ngôn ngữ và các phương tiện khác như kí hiệu, sơ đồ, biểu đồ, hình ảnh, âm thanh" [1].

(2) Chương trình 2018 đã nêu ra quan điểm về năng lực văn học đối với học sinh phổ thông. Theo chương trình, năng lực văn học là " $m o ̂ t t$ biểu hiện của năng lực thẩm mĩ, là khả năng nhận biết, phân tích, tái hiện và sáng tạo các yếu tố thẩm mĩ thông qua hoạt động tiếp nhận và tạo lạp văn bản văn hoc" (tr.87). Để hình thành và phát triển năng lực văn học cho học sinh phổ thông, Chương trình 2018 nêu ra những nội dung và yêu cầu cần đạt về đọc hiểu văn bản và tạo lập văn bản gồm những điểm mới so với Chương trình 2006. Chẳng hạn:

- Với học sinh cấp trung học cơ sở, chương trình yêu cầu học sinh "bước đầu tạo ra được một số sản phẩm có tính văn học" (tr.10) như làm thơ lục bát, làm thơ bốn chữ hoặc năm chữ, làm thơ tự do (sáu, bảy chữ), làm thơ tám chữ; biết kể một truyện cười; biết kể các câu chuyện có yếu tố kì ảo hoang đường...

- Với học sinh cấp trung học phổ thông, chương trình yêu cầu học sinh "nhận biết được đặc trưng của hình tượng văn học và một số điểm khác biệt giữa hình tượng văn học với các loại hình tượng nghệ thuật khác (hội hoạ, âm nhạc, kiến trúc, điêu khắc" [1]; "tạo lập được một số kiểu văn bản văn học thể hiện khả năng biểu đạt cảm xúc và ý tưởng bằng hình thức ngôn từ mang tính thẩm mĩ" [1]; "viết được văn bản nghị luận về một tác phâm văn học hoặc một bộ phim, bài hát, bức tranh, pho tượng [1]; "biết giới thiệu một tác phẩm nghệ thuật theo lựa chọn cá nhân (ví dụ: tác phẩm văn học, tác phẩm điện ảnh, âm nhạc, hội hoạ) ... [1]. Đặc biệt, Chương trình 2018 đưa ra 2 chuyên đề để dạy học nhằm phát triển năng lực văn học cho học sinh, bao gồm:

+ Chuyên đề "Sân khấu hóa tác phẩm văn hoc", trong đó chương trình nêu yêu cầu cần đạt đối với học sinh, bao gồm: Hiểu thế nào là sân khấu hoá tác phẩm văn học; Biết cách tiến hành sân khấu hoá một tác phẩm văn học; Biết đóng vai các nhân vật và biểu diễn; Nhận biết được sự khác biệt giữa ngôn ngữ trong văn bản văn học và ngôn ngữ trong văn bản sân khấu. Để thực hiện được yêu cầu đó, giáo viên tập trung vào dạy học sinh các nội dung sau: (1) Tác phẩm văn học và sân khấu hoá tác phẩm văn học; (2) Quy trình tiến hành sân khấu hoá một tác phẩm văn học; (3) Cách nhập vai, diễn xuất, thực hành sân khấu hoá tác phẩm văn học; (4) Ngôn ngữ trong văn bản văn học và ngôn ngữ (đa phương thức) trong văn bản sân khấu [1]. 
+ Chuyên đề "Tìm hiểu về một tác phẩm nghệ thuật chuyển thể từ văn học", trong đó chương trình nêu yêu cầu cần đạt đối với học sinh, bao gồm: Hiểu thế nào là chuyển thể tác phẩm văn học; Biết cách tìm hiểu, giới thiệu, thuyết trình về một tác phẩm nghệ thuật được chuyển thể từ văn học; Nêu được ý tưởng và cách thức tiến hành chuyển thể một tác phẩm văn học. Để thực hiện được yêu cầu đó, giáo viên tập trung vào dạy học sinh các nội dung sau: (1) Tác phẩm văn học và chuyển thể tác phẩm văn học; (2) Một số điểm khác biệt cơ bản giữa tác phẩm văn học và tác phẩm chuyển thể từ tác phẩm văn học; (3) Cách chuyển thể một tác phẩm văn học thành bộ phim, tác phẩm hội hoạ, âm nhạc,... [1].

(3) Chương trình 2018 nêu phương pháp dạy học đối với giáo viên, trong đó nhấn mạnh đển việc giáo viên hướng dẫn "kể chuyện, đóng vai để giải quyết một tình huống, diễn kịch, ... chuyển thể tác phẩm văn học từ thể loại này sang thể loại khác, vẽ tranh, làm phim, trải nghiệm những tình huống mà nhân vật đã trải qua,... [1].

Như vậy, để khi ra trường có thể dạy học đáp ứng yêu cầu của Chương trình 2018 , sinh viên ngành Sư phạm Ngữ văn ngoài việc được trang bị những kiến thức và kĩ năng về ngôn ngữ và văn học để dạy học những nội dung quen thuộc, rất cần được bổ sung thêm những kiến thức, kĩ năng về dạy học văn bản thông tin, đặc biệt là cách "chuyển thể tác phẩm văn học thể loại này sang thể loại khác, vẽ tranh, làm phim" cũng như "sân khấu hóa văn học"... Muốn làm được điều đó, chương trình đào tạo cử nhân ngành Sư phạm Ngữ văn của các trường đại học cần có sự điều chỉnh về chuẩn đầu ra và các học phần của chương trình đào tạo.

\section{Chương trình đào tạo hệ cử nhân ngành Sư phạm Ngữ văn của một số trường đại học trong nước}

Đa số học sinh ở trường phổ thông của Việt Nam hiện nay sau khi tốt nghiệp trung học phổ thông vẫn chưa có năng lực ngôn ngữ và năng lực văn học (hiểu theo nghĩa đầy đủ nhất của hai năng lực này). Mục tiêu của dạy học Ngữ văn ở trường phổ thông hầu như chưa đạt được do nhiều nguyên nhân, trong đó có việc hiểu chưa đúng bản chất của môn học và chưa có cách dạy học, kiểm tra đánh giá hợp lí. Một trong những nguyên nhân của hiện tượng này chính là trình độ của giáo viên, có liên quan đến khâu đào tạo giáo viên Ngữ văn ở các trường đại học sư phạm.

Hiện nay, chương trình đào tạo cử nhân ngành Sư phạm Ngữ văn của một số trường đại học sư phạm chưa điều chỉnh chuẩn đầu ra và chưa có đầy đủ những học phần với nội dung thích hợp để giúp sinh viên sau khi ra trường có thể đáp ứng được những yêu cầu nêu trên của Chương trình 2018. Cụ thể là, chương trình đào tạo cử nhân ngành Sư phạm Ngữ văn của các trường đại học đều có những học phần khá giống nhau nhằm cung cấp các kiến thức chung, kiến thức theo lĩnh vực, kiến thức theo khối ngành, kiến thức theo nhóm ngành và kiến thức ngành. Hầu hết các học phần thuộc khối kiến thức theo nhóm ngành và ngành đều nhằm trang bị cho sinh viên những kiến thức về ngôn ngữ và văn học. Các nội dung về ngôn ngữ và văn học mà sinh viên được học đều là những thành tựu nghiên cứu của nhiều năm trước, chưa cập nhật những nghiên cứu về văn bản (nhất là văn bản thông tin) và về văn học (nhất là văn học kĩ thuật số). Các chương trình đào tạo này cũng không coi trọng và chưa cung cấp cho sinh viên kiến thức về mảng văn học dành cho thiếu nhi. Đặc biệt, các kiến thức về ngành (nhất là kiến thức trong các học phần về phương pháp dạy học) khá cũ kĩ, chủ yếu giúp sinh viên sau khi ra trường đáp ứng yêu cầu về phương pháp dạy học Ngữ văn theo quy định của Chương trình 2006 (thiên về dạy học theo lối cung cấp kiến thức, dạy học đọc hiểu và tạo lập các kiểu văn bản truyền thống).

Hiện nay, trong chương trình đào tạo của các trường đại học sư phạm có một số học phần thể hiện tính "liên ngành" nhằm giúp sinh viên 
có khả năng dạy học Ngữ văn tích hợp với các môn nghệ thuật khác hoặc tổ chức hoạt động trải nghiệm cho học sinh phổ thông. Chẳng hạn, chương trình đào tạo cử nhân ngành Sư phạm Ngữ văn của Trường Đại học Sư phạm Hà Nội có học phần "Âm nhạc", "Mỹ học và giáo dục thẩm mỹ", "Nghệ thuật học đại cương" [2]; Chương trình của Trường Đại học Giáo dục Đại học Quốc gia Hà Nội có học phần "Nghệ thuật học đại cương" [3]; Chương trình của Trường Đại học Sư phạm Hà Nội 2 có học phần "Văn học và các loại hình nghệ thuật" [4]; Chương trình đào tạo của Trường Đại học Sư phạm - Đại học Thái Nguyên có học phần "Âm nhạc, nghệ thuật tạo hình với văn học", "Tổ chức hoạt động trải nghiệm sáng tạo trong dạy học môn Ngữ văn ở trường phổ thông" [5]; Chương trình đào tạo của Trường Đại học Sư phạm Thành phố Hồ Chí Minh có học phần tự chọn "Nghệ thuật học", "Hoạt động trải nghiệm sáng tạo trong dạy học Ngữ văn" [6] ... Tuy nhiên, tất cả các học phần kể trên của các trường đều là học phần tự chọn, mang tính lí thuyết là chính, ít tính thực hành. Chưa có chương trình đào tạo nào có học phần dạy riêng về văn bản thông tin và dạy học văn bản thông tin; chưa có các học phần về văn học thiếu nhi hay văn học kĩ thuật số; cũng chưa có các học phần hướng dẫn học sinh phổ thông diễn kịch, chuyển thể tác phẩm văn học từ thể loại này sang thể loại khác, vẽ tranh, làm phim... Nhiều sinh viên ngành Sư phạm Ngữ văn tốt nghiệp trung học phổ thông nhưng chưa thực sự có năng lực đọc hiểu và tạo lập văn bản thông tin, cũng không phải sinh viên nào cũng có năng khiếu nghệ thuật (hát, vẽ tranh, làm thơ, diễn kịch...). Nói cách khác, nền tảng học vấn phổ thông chưa đủ để giúp sinh viên thực hiện được các yêu cầu của Chương trình 2018. Nếu chương trình đào tạo của các trường đại học sư phạm không hình thành và phát triển cho sinh viên những năng lực này thì họ khó có thể đáp ứng được yêu cầu của việc dạy học Ngữ văn ở nhà trường phổ thông trong thời gian tới.

\section{Chương trình đào tạo hệ cử nhân ngành Sư phạm Ngữ văn của một số trường đại học trên thế giới}

Ở các nước tiên tiến trên thế giới như Mỹ, Canada, Úc, Anh, Singapore... , từ bậc học phổ thông, HS đã được hình thành và phát triển năng lực tiếp nhận và tạo lập văn bản, đã được thường xuyên đọc và viết văn bản đa phương tiện (kể cả văn bản văn học kĩ thuật số), diễn kịch, chuyển thể tác phẩm văn học từ thể loại này sang thể loại khác, vẽ tranh, làm phim... Nghĩa là, trước khi trở thành sinh viên ngành Sư pham Ngữ văn, họ đã được trang bị nền tảng học vấn phổ thông vững chắc về những vấn đề trên. Để trở thành sinh viên dạy học môn ngôn ngữ và văn học, sinh viên ở các nước trên được học theo chương trình đào tạo có sự chú trọng việc trang bị cho họ năng lực dạy học văn bản thông tin, năng lực dạy văn học cho thiếu nhi, năng lực nghiên cứu và biểu diễn nghệ thuật... Đặc biệt, các chương trình đào tạo không chỉ giúp sinh viên đáp ứng được yêu cầu của công việc ở thời điểm mà họ tốt nghiệp đại học, mà còn giúp họ có thể thích ứng được với những đổi thay của việc dạy học Ngữ văn trong tương lai. Nói cách khác, chương trình đào tạo ở các nước trên có tầm nhìn dài hạn, thể hiện triết lí giáo dục cho tương lai chứ không chỉ chạy theo những đòi hỏi của thực tiễn ở thời điểm hiện tại.

Dưới đây là một số học phần chính, riêng biệt có trong chương trình đào tạo cử nhân sư phạm Ngữ văn của một số trường đại học trên thế giới giúp sinh viên sau khi tốt nghiệp có thể dạy học để phát triển năng lực ngôn ngữ và năng lực văn học cho học sinh phổ thông. Ngoài các học phần này, sinh viên vẫn được học các học phần liên quan đến ngôn ngữ, văn học, khoa học tự nhiên và kĩ thuật, khoa học xã hội... để có đầy đủ kiến thức và kĩ năng đáp ứng yêu cầu của công việc trong tương lai. 
Bảng: Tên một số học phần trong chương trình đào tạo ngành Sư phạm Ngữ văn của một số trường đại học trên thế giới

\begin{tabular}{|c|c|c|}
\hline Trường đại học & Quốc gia & Tên học phần \\
\hline Trường Đại học New South & Úc & - Kịch \\
\hline Wales (The University of New & & - Nghiên cứu âm nhạc \\
\hline South Wales) [7] & & - Văn học kĩ thuật số \\
\hline Trường Đại học Sydney (The & Úc & - Âm nhạc kỹ thuật số nâng cao \\
\hline University of Sydney) [8] & & $\begin{array}{l}\text { - Hòa âm nâng cao } \\
\text { - Thẩm mỹ và nghê thuât }\end{array}$ \\
\hline $\begin{array}{l}\text { Trường Đại học Công nghệ } \\
\text { Sydney (Universtity of } \\
\text { Technology Sydney) [9] }\end{array}$ & Úc & Nghệ thuật thị giác, Âm nhạc, di chuyển và khiêu vũ \\
\hline $\begin{array}{l}\text { Trường Đại học Edith Cowan } \\
\text { (Edith Cowan University) [10] }\end{array}$ & Úc & $\begin{array}{l}\text { - Thanh thiếu niên và truyền thông toàn cầu } \\
\text { - Từ tiểu thuyết đến phim } \\
\text { - Tiểu thuyết đồ họa } \\
\text { - Văn học ảo cho trẻ em }\end{array}$ \\
\hline $\begin{array}{l}\text { Trường Đại học Victoria ở } \\
\text { Wellington (Vitoria University } \\
\text { of Wellington) [10] }\end{array}$ & New Zealand & Nghệ thuật thị giác và biểu diễn \\
\hline $\begin{array}{l}\text { Trường Đại học Massey } \\
\text { (Massey University) [12] }\end{array}$ & New Zealand & $\begin{array}{l}\text { - Giới thiệu về nghiên cứu truyền thông } \\
\text { - Viết sáng tạo } \\
\text { - Viết thơ } \\
\text { - Kịch trong trình diễn } \\
\text { - Viết cho công chúng } \\
\text { - Dự án xuất bản } \\
\text { - Văn học kĩ thuật số }\end{array}$ \\
\hline $\begin{array}{l}\text { Trường Đại học Augusta } \\
\text { (Augusta University) [13] }\end{array}$ & Mỹ & $\begin{array}{l}\text { - Phim } \\
\text { - Âm nhạc } \\
\text { - Sân khẩu và biểu diễn }\end{array}$ \\
\hline $\begin{array}{l}\text { Trường Đại học Kansas (The } \\
\text { University of Kansas) [14] }\end{array}$ & Mỹ & $\begin{array}{l}\text { - Diễn giả và khán giả trong truyền thông } \\
\text { - Văn học liên văn hóa } \\
\text { - Sáng tạo nâng cao }\end{array}$ \\
\hline
\end{tabular}

\section{Một số giải pháp đổi mới và nâng cao chất lượng đào tạo cử nhân Sư phạm Ngữ văn ở nước ta trong thời gian tới}

Để hình thành và phát triển năng lực cho học sinh ở trường phổ thông, đặc biệt là năng lực ngôn ngữ và năng lực văn học, giáo viên cũng phải là người có những năng lực này. Vì vậy, không nên để tình trạng chương trình đào tạo của các trường đại học đi sau, lạc hậu hơn và "chạy theo" chương trình giáo dục phổ thông mà phải đi trước, đón đầu, định hướng cho giáo dục phổ thông trong tương lai.

Trong bối cảnh hiện nay, để đáp ứng yêu cầu của Chương trình 2018 và những đổi thay trong thời gian tới, cần thực hiện một số giải pháp dưới đây để đổi mới và nâng cao chất lượng đào tạo nhân ngành Sư phạm Ngữ văn ở các trường đại học sư phạm:

- Rà soát, điều chỉnh chuẩn đầu ra của chương trình đào tạo theo hướng vừa đáp ứng yêu cầu của Chương trình Ngữ văn 2018 và thể hiện tầm nhìn dài lâu để phù hợp với những đổi thay của chương trình giáo dục phổ thông trong tương lai.

- Cập nhật nội dung của các học phần thuộc khối kiến thức ngành, liên quan đến ngôn ngữ và văn học. Hiện nay, nhiều học phần của khối kiến thức này có nội dung cũ kĩ, chưa cập nhật được các thành tựu mới trong nghiên cứu và giảng dạy Ngữ văn ở trường phổ thông. 
- Điều chỉnh, bổ sung nội dung cho các học phần thuộc khối kiến thức ngành, liên quan trực tiếp đến phương pháp dạy học và kiểm tra, đánh giá khả năng đọc, viết, nói và nghe cho học sinh phổ thông theo hướng: bổ sung các nội dung liên quan văn bản thông tin (nhất là loại văn bản đa phương tiện), văn bản văn học nhằm phát triển năng lực cho người học; tăng cường các phương pháp dạy học và kiểm tra đánh giá theo hướng tôn trọng sự khác biệt, sự sáng tạo, suy nghĩ độc lập, cảm thụ riêng, cá thể hóa... của người học; tăng tín chỉ cho các học phần này.

- Xây dựng mới một số học phần bắt buộc hướng dẫn sinh viên đọc, viêt, nói và nghe về văn bản thông tin (bởi khả năng này của nhiều sinh viên ngành Sư phạm Ngữ văn hiện nay còn yếu, nhất là những sinh viên có điểm xét tuyển vào đại học còn thấp); các học phần hướng dẫn sinh viên sáng tác văn học, sân khấu hóa tác phẩm văn học, chuyển thể tác phẩm văn học, ứng dụng công nghệ thông tin, truyền thông, tổ chức các hoạt động trải nghiệm cho học sinh, sử dụng các di sản của Việt Nam và thế giới trong dạy học...

- Đổi mới khâu tuyển sinh hệ cử nhân ngành Sư phạm Ngữ văn theo hướng có thêm hình thức sơ tuyển để tuyển chọn được những người học có năng khiếu nghệ thuật vào học ngành Sư phạm Ngữ văn, đáp ứng được những yêu cầu của dạy học Ngữ văn ở trường phổ thông theo hướng phát triển năng lực.

Ngoài ra, các trường đại học sư phạm cần có những chương trình bồi dưỡng thường xuyên, định kì cho giáo viên Ngữ văn ở trường phổ thông về dạy học Ngữ văn theo định hướng phát triển năng lực, nhất là năng lực văn học cho học sinh.

\section{Kết luận}

Dạy học Ngữ văn ở trường phổ thông vừa là một công việc mang tính khoa học, vừa mang tính nghệ thuật, trong đó, tính nghệ thuật góp phần tạo nên đặc trưng riêng của môn học này.
Vì thế, cần thay đổi cách tiếp cận môn học và phương pháp dạy học Ngữ văn ở trường phổ thông. Muốn như vậy, chương trình đào tạo cử nhân ngành Sư phạm Ngữ văn của các trường đại học sư phạm phải đi đầu trong việc đổi mới để nâng cao chất lượng đào tạo, cho "ra lò" những giáo viên có trình độ, đáp ứng được yêu cầu của thực tiễn và bản chất của môn học.

\section{Tài liệu tham khảo}

[1] Bộ Giáo dục và Đào tạo, Chương trình giáo dục phổ thông môn Ngữ văn (http://rgep.moet.gov.vn/chuong-trinh-gdptmoi/chuong-trinh-cac-mon-hoc/chuong-trinhmon-ngu-van-4729.html/, 2018 (truy cập ngày 157-2019).

[2] Trường Đại học Sư phạm Hà Nội, Khung chương trình chuyên ngành Sư phạm Ngữ văn (http://www.hnue.edu.vn/Daotao/Khungchuongtri nh/CunhanSupham/tabid/428/frame/27/Default.as px/, 2019 (truy cập ngày 15-7-2019).

[3] Trường Đại học Giáo dục, Bản mô tả chương trình đào tạo Cử nhân Sư phạm Ngữ văn (https://education.vnu.edu.vn/files/Tin\%20tuc/2. \%20Dao\%20tao/20041216044040288.pdf/, 2019 (truy cập ngày 15-7-2019).

[4] Trường Đại học Sư phạm Hà Nội 2, Khung chương trình đào tạo hệ chính quy theo hệ thống tín chỉ. (http://www.hpu2.edu.vn/vi/dao-tao/chuong-trinhdao-tao-chi-tiet-tu-k41/su-pham-ngu-van-132.html/, 2019 (truy cập ngày 15-7-2019).

[5] Trường Đại học Sư phạm - Đại học Thái Nguyên, Bản mô tả chương trình đào tạo Cử nhân Sư phạm Ngữ văn. (http://khoavan.dhsptn.edu.vn/869_Banmo-ta-Chuong-trinh-dao-tao-Cu-nhan-Su-phamNgu-van.html/, 2019 (truy cập ngày 15-7-2019).

[6] Trường Đại học Sư phạm Thành phố Hồ Chí Minh, Chương trình giáo dục Đại học Sư phạm Ngữ văn.

(http://hcmup.edu.vn/index.php?option=com_cont ent\&view=article \&id=22163\%3A2016-11-24-01$35-37 \&$ catid $=156 \% 3$ Athong-bao-

khn\&Itemid=316\&lang=vi\&site=13/, 2019 (truy cập ngày 15-7-2019).

[7] http://legacy.handbook.unsw.edu.au/undergraduat e/programs/2018/4053.html/, 2019 (truy cập ngày 15-7-2019).

[8] https://sydney.edu.au/courses/uoslanding.page1.ye $\operatorname{ar} 0 . \mathrm{html} /$ content/courses/courses/uc/bachelor-of- 
education-secondary-humanities-and-socialsciences-and-bachelor-of-arts.html\#0/, 2019 (truy cập ngày 15-7-2019).

[9] http://handbook.uts.edu.au/courses/c10350.html/, 2019 (truy cập ngày 30-8-2019).

[10] https://www.ecu.edu.au/handbook/unitset?year=2 019\&id=MABUTM/, 2019 (truy cập ngày 15-72019)

[11] https://www.victoria.ac.nz/explore/degrees/arts/ov erview?major=tesol\&fbclid=IwAR1g8bFRX0fHL Ots-

TLfrZJacnDYs3jK7dCqy9O8ybvY0DeX4t5FeX D6_0w/, 2019 (truy cập ngày 15-7-2019).

[12] https://www.massey.ac.nz/massey/learning/pr ogramme- course/programme.cfm?prog_id=93118\&maj or $\_$code $=$PENGL $\&$ tab $=$ plan $\&$ fbclid $=I w A R 0 b$ BHO4OvDjiG17YRAF3BadCVZ1 mXxtUSS2 WKOEyJWP7zfWzRWOs1_vpkU/, 2019 (truy cập ngày 15-7-2019).

[13] https://www.augusta.edu/pamplin/english-foreignlanguages/documents/01242018engllitsecedtracks heet.pdf?fbclid=IwAR3ntmJPHaftnjIIKJ3DWqxp FLNsrE1GxCJ-_2jLZ71DS7mOwLkTTJkeRNY/, 2019 (truy cập ngày 15-7-2019).

[14] https://ct.ku.edu/academics/teachereducation/secondary-english/bachelors degree/program-curriculum/, 2019 (truy cập ngày 15-7-2019). 